\title{
Clarithromycin-Loaded Ocular Chitosan Nanoparticle: Formulation, Optimization, Characterization, Ocular Irritation, and Antimicrobial Activity
}

This article was published in the following Dove Press journal:

International Journal of Nanomedicine

\author{
May Bin-Jumah (D) \\ Sadaf Jamal Gilani ${ }^{2}$ \\ Mohammed Asadullah \\ Jahangir $\left(\mathbb{D}^{3}\right.$ \\ Ameeduzzafar Zafar ${ }^{4}$ \\ Sultan Alshehri (iD ${ }^{5,6}$ \\ Mohd Yasir (iD ${ }^{7}$ \\ Chandra Kala (iD ${ }^{8}$ \\ Mohamad Taleuzzaman ${ }^{8}$ \\ Syed Sarim Imam $\mathbb{D}^{5}$ \\ 'Biology Department, College of Science, \\ Princess Nourah Bint Abdulrahman \\ University, Riyadh, Saudi Arabia; \\ ${ }^{2}$ Department of Basic Health Sciences, \\ Princess Nourah Bint Abdulrahman \\ University, Riyadh, Saudi Arabia; \\ ${ }^{3}$ Department of Pharmaceutics, Nibha \\ Institute of Pharmaceutical Sciences, Rajgir, \\ Nalanda 803 I 6, Bihar, India; ${ }^{4}$ Department \\ of Pharmaceutics, College of Pharmacy, Jouf \\ University, Sakaka, Aljouf, Saudi Arabia; \\ ${ }^{5}$ Department of Pharmaceutics, College of \\ Pharmacy, King Saud University, Riyadh, \\ Saudi Arabia; ${ }^{6}$ College of Pharmacy, \\ Almaarefa University, Riyadh, Saudi Arabia; \\ ${ }^{7}$ Department of Pharmacy, College of Health \\ Science, Arsi University, Asella, Ethiopia; \\ ${ }^{8}$ Faculty of Pharmacy, Maulana Azad \\ University, Jodhpur 342802, Rajasthan, India
}

Correspondence: Sadaf Jamal Gilani Department of Basic Health Sciences, Princess Nourah Bint Abdulrahman University, Riyadh, Saudi Arabia Email gilanisadaf@gmail.com

Syed Sarim Imam

Department of Pharmaceutics, College of Pharmacy, King Saud University, Riyadh,

Saudi Arabia

Email sarimimam@gmail.com
Purpose: The topically administered drugs through conventional delivery systems have low bioavailability. Henceforth, the present study was designed to prepare and optimize clarithromycin (CTM)-loaded chitosan nanoparticles (CHNPs) to demonstrate the efficacy against microorganisms.

Methods: Clarithromycin-loaded chitosan nanoparticles (CTM-CHNPs) were prepared by ionotropic gelation method. The formulation was optimized by box-Behnken design using the formulation variables like CH (A), STPP concentration (B), and stirring speed (C). Their effects were evaluated on the independent variables like particle size $\left(\mathrm{Y}_{1}\right)$ and entrapment efficiency $\left(\mathrm{Y}_{2}\right)$. Further, CTM-CHNPs were evaluated for physicochemical parameters, invitro drug release, ex-vivo permeation, bioadhesive study, corneal hydration, histopathology, HET-CAM, and antibacterial study.

Results: The optimized formulation (CTM-CHNPopt) showed the low particle size $(152 \pm 5$ $\mathrm{nm})$, which is desirable for ocular delivery. It also showed high encapsulation (70.05\%), zeta potential $(+35.2 \mathrm{mV})$, and was found in a spherical shape. The drug release study revealed a sustained drug release profile $(82.98 \pm 3.5 \%$ in 12 hours) with Korsmeyer peppas kinetic $\left(\mathrm{R}^{2}=0.996\right)$ release model. It showed a 2.7 -fold higher corneal permeation than CTMsolution. CHNPs did not exhibit any sign of damage to excised goat cornea, which is confirmed by hydration, histopathology, and HET-CAM test. It exhibited significant $(P<0.05)$ higher antibacterial susceptibility than CTM-solution.

Conclusion: The finding of the study concluded that CTM-CHNPs can be used for effective management of bacterial conjunctivitis by increasing the precorneal residence time.

Keywords: clarithromycin, chitosan, optimization, nanoparticles, HET-CAM, antimicrobial assessment

\section{Introduction}

The eye is the most common and accessible site for topical drug administration. The drugs can be instilled to the ocular region for the local as well as systemic action 1 . The delivery of drugs to the eye has been a challenging task due to their complex anatomy and physiology. The anterior region of the eye is the cornea, comprised of the epithelium, stroma, and endothelium. This layer acts as a mechanical barrier for the drug delivery systems. The presence of high lipid content in the epithelium and endothelium obstruct the passage of hydrophilic molecules. The stroma contains 
high water content and makes it difficult for the entry of the lipophilic molecule. ${ }^{1,2}$ The main challenge for the researcher is to overcome these barriers without causing any damage. There are different colloidal systems gaining wide acceptance due to the lesser dose administration, avoidance of ocular irritation, and reduced patient discomfort. ${ }^{3,4}$ These delivery systems exhibit fast clearance and lead to short residence times. The use of bioadhesive polymers can increase the residence time in the ocular region. The bioadhesive polymeric colloidal delivery systems have reported an enhancement of bioavailability of the drug by 1.7 -fold as compared to other polymers. ${ }^{5}$

There are various polymeric nano-formulations which have been explored to enhance drug retention and permeation. These are widely accepted due to their biodegradable and non-toxic nature. The different polymers are used for ocular polymeric nanoparticles, ie, tamarind kernel polysaccharide, ${ }^{6}$ eudragit RS- $100,{ }^{7}$ sodium alginate, ${ }^{8}$ pectin, ${ }^{9}$ chitosan, ${ }^{10}$ and galactomannan. ${ }^{11}$ Among these, chitosan $(\mathrm{CH})$ is a well-known and most prominently used polymer in different ocular delivery systems. ${ }^{12}$ It is a natural cationic polysaccharide polymer obtained from the deacetylation of chitin. ${ }^{13}$ Moreover, $\mathrm{CH}$ has a strong bioadhesive property, and overcomes the rapid elimination from the ocular region by increasing the corneal contact time. The formulation prepared with $\mathrm{CH}$ produces less viscosity than a conventional viscolizer. It is soluble in acidic medium and transformed into protonated form $\left(\mathrm{NH}_{3}{ }^{+}\right)$. The presence of a positive charge on $\mathrm{CH}$ at the physiological $\mathrm{pH}$ is the main advantage. It interacts with the negative charge of mucin and helps to enhance the bioadhesion. It has shown promising results in ocular delivery due to the longer corneal surface retention. It is also reported to be antibacterial by acting on the cell wall of bacteria. ${ }^{14,15}$ It enhances the blood clotting by possessing hemostatic properties. ${ }^{16}$ The structure of $\mathrm{CH}$ with the $\mathrm{NH}_{3}{ }^{+}$group adsorb on the cell wall of the microorganisms by the electrostatic interaction. It leads to damage of the cell wall integrity and leakage of macromolecules from bacteria. ${ }^{17}$ The interaction with the outer membrane of Gram-negative bacteria with chitosan may contribute to enhancing antibacterial activities. ${ }^{18}$

Clarithromycin (CTM) is a second-generation broadspectrum macrolide antibiotic, effective against Gramnegative and Gram-positive microorganism, as well as intracellular pathogens. It is topically used to treat experimental Mycobacterium fortuitum, Mycobacterium chelonae keratitis, and Staphylococcus aureus keratitis in an animal model. ${ }^{19}$ It is a poorly water-soluble drug and has a half-life of 3-4 hours, hence frequent dosing is required. ${ }^{20}$ It inhibits the bacterial protein synthesis by binding with the ribosome (50S) of bacteria and interferes with the amino-acid translocation for the synthesis of protein.

The objective of the present study was to prepare CTM-loaded CHNPs by ionotropic gelation method. The formulation was optimized by a quality by design (QbD) approach using three factors at three levels. Further, the optimized CTM-loaded CHNPs formulation was evaluated for solid-state characterization, in-vitro drug release, mucoadhesive strength, ex-vivo permeation, ocular tolerance, and antimicrobial assessment.

\section{Materials and Methods Materials}

Chitosan (MW 120,000, deacetylation degree 85\%) derived from crab shell, was procured from Indian Sea Food (Kochi, India). Sodium tripolyphosphate (STPP) was procured from SD fine chemical (Mumbai, India). Clarithromycin (CTM) was obtained from Merck (Mumbai, India). Pig mucin was purchased from Himedia (Mumbai, India). Glacial acetic acid and phosphate buffer chemical were procured from Sigma Aldrich. All other chemicals used for the research were of analytical grade.

\section{Method of Preparation}

The ionotropic gelation method was employed for the formulation of CTM-CHNPs. ${ }^{21}$ The composition of a total of 17 formulations was taken as per the BBD design and are shown in Table 1. The different concentration of $\mathrm{CH}(0.1-0.35 \%)$ was dissolved in the aqueous glacial acetic acid $(1 \% \mathrm{v} / \mathrm{v})$ solution. Separately, the different concentration of STPP $(0.1-0.4 \%)$ was dissolved in double-distilled water. The calculated amount of CTM (25 $\mathrm{mg}$ ) was dissolved in $\mathrm{CH}$ solution and added dropwise to STPP solution with continuous stirring (1000-2500 rpm). The prepared NPs were separated by ultracentrifugation technique (Remi 24, Cooling centrifuge, Mumbai, India) at 15,000 rpm and separated. They were then washed with distilled water and lyophilized (Heto-powder dry LL1500 freeze dryer, Thermo electronic, Germany) using mannitol $(2 \% \mathrm{w} / \mathrm{w})$ as a cryoprotectant. The lyophilized sample was collected and stored for further characterization.

\section{Optimization}

As per preliminary study results, the formulation was optimized by Box-Behnken design using software (Design 
Table I Clarithromycin-Loaded Chitosan Nanoparticles Composition and Their Effect on Particle Size $\left(\mathrm{Y}_{\mathrm{I}}\right)$ and Entrapment Efficiency $\left(\mathrm{Y}_{2}\right)$

\begin{tabular}{|c|c|c|c|c|c|c|c|}
\hline \multirow[t]{3}{*}{ Formulation } & \multicolumn{3}{|c|}{ Independent Variables } & \multicolumn{4}{|c|}{ Responses } \\
\hline & \multirow[t]{2}{*}{$\begin{array}{l}\mathbf{A}-\mathbf{C H}(\%, \\
w / v)\end{array}$} & \multirow[t]{2}{*}{$\begin{array}{l}\text { B - STPP (\%, } \\
\text { w/v) }\end{array}$} & \multirow[t]{2}{*}{$\begin{array}{l}\text { C - Stirring Speed } \\
(\mathrm{rpm})\end{array}$} & \multicolumn{2}{|c|}{ Particle Size $\left(\mathrm{nm}, \mathbf{Y}_{\mathrm{I}}\right)$} & \multicolumn{2}{|c|}{$\begin{array}{l}\text { Entrapment Efficiency (\%, } \\
\left.\mathbf{Y}_{2}\right)\end{array}$} \\
\hline & & & & $\begin{array}{l}\text { Actual } \\
\text { Value }\end{array}$ & $\begin{array}{l}\text { Predicted } \\
\text { Value }\end{array}$ & $\begin{array}{l}\text { Actual } \\
\text { Value }\end{array}$ & $\begin{array}{l}\text { Predicted } \\
\text { Value }\end{array}$ \\
\hline I & 0.10 & 0.1 & 2500 & 115.79 & 115.55 & 40.12 & 40.07 \\
\hline 2 & 0.35 & 0.1 & 2500 & 246.43 & 246.62 & 48.47 & 48.53 \\
\hline 3 & 0.10 & 0.4 & 2500 & 110.42 & 110.22 & 70.33 & 70.27 \\
\hline 4 & 0.35 & 0.4 & 2500 & 186.14 & 186.38 & 61.54 & 61.58 \\
\hline 5 & 0.10 & 0.25 & 1000 & 171.92 & 172.37 & 57.16 & 57.15 \\
\hline 6 & 0.35 & 0.25 & 1000 & 283.75 & 283.77 & 68.09 & 67.97 \\
\hline 7 & 0.10 & 0.25 & 4000 & 116.80 & 116.77 & 47.43 & 47.54 \\
\hline 8 & 0.35 & 0.25 & 4000 & 209.08 & 208.62 & 36.49 & 36.49 \\
\hline 9 & 0.22 & 0.1 & 1000 & 202.34 & 202.12 & 54.60 & 54.65 \\
\hline 10 & 0.22 & 0.4 & 1000 & 173.32 & 173.05 & 72.06 & 72.13 \\
\hline II & 0.22 & 0.1 & 4000 & $|38.2|$ & 138.47 & 30.02 & 29.95 \\
\hline 12 & 0.22 & 0.4 & 4000 & 102.26 & 102.97 & 55.79 & 55.74 \\
\hline$* 13$ & 0.22 & 0.25 & 2500 & 154.12 & 154.10 & 51.98 & 52.30 \\
\hline$* 14$ & 0.22 & 0.25 & 2500 & 153.54 & 154.10 & 52.23 & 52.30 \\
\hline$* 15$ & 0.22 & 0.25 & 2500 & 155.30 & 154.10 & 52.65 & 52.30 \\
\hline$* 16$ & 0.22 & 0.25 & 2500 & 154.32 & 154.10 & 52.43 & 52.30 \\
\hline$* 17$ & 0.22 & 0.25 & 2500 & 153.26 & 154.10 & 52.24 & 52.30 \\
\hline
\end{tabular}

Note: *Center point, having same composition.

Expert 7.0.0). The independent variables $\mathrm{CH}(\mathrm{A})$, STPP concentration (B), and stirring speed (C) were taken at three different levels [low (-), medium (0), high (+)]. The effect of independent variables was assessed on the dependent variables to evaluate the different model. The independent variables [particle size $\left(\mathrm{X}_{1}\right)$ and encapsulation efficiency $\left(\mathrm{X}_{2}\right)$ ] were evaluated to assess the effect of each response. The design showed a total of 17 runs with five common formulations, as shown in Table 1. The responses of different formulations were fitted into the linear, 2nd order, and quadratic model for the identification of the best fit model. The polynomial equation and three-dimensional surface plots were generated to check the effect of independent variables on the dependent variables.

\section{Characterization}

\section{Particle characterization}

The prepared CTM-CHNPs were evaluated for size, polydispersibility index (PDI), and zeta potential (ZP) by zeta sizer (Malvern zeta sizer nano, Malvern UK). The evaluation was performed by taking the sample $(0.1 \mathrm{~mL})$, diluted (100 times) with double distilled water and then evaluated for the mentioned parameters. The morphological examination of optimized nanoparticle (CTM-CHNPopt) was done by using transmission electron microscopy (JEM1011, JEOL, Inc., Peabody, MA, USA). A drop of the sample was placed over the copper-coated grid and phosphotungstic acid $(2 \% \mathrm{v} / \mathrm{v})$ was applied over the formulation as a staining agent. The excess volume was removed, air-dried, and then the sample was placed to evaluate the particle morphology.

\section{Thermal Analysis}

The thermal analysis of CTM, CH, and CTM-CHNPopt were performed using the DSC instrument (DSC 6000, Perkin Elmer, Waltham, MA 02451, USA). The appropriate quantity $(\sim 5 \mathrm{mg})$ of each sample was taken in a sample pan and sealed. The sealed samples were placed into a DSC instrument and scanned between $0-300^{\circ} \mathrm{C}$ at a scanning speed of $5^{\circ} \mathrm{C} / \mathrm{min}$ with a continuous supply of nitrogen.

\section{X-Ray Diffraction Study}

The diffractogram of CTM, CH, and CTM-CHNPopt were analyzed by the x-ray diffraction machine (Philips PW 3710, Eindhoven, Netherlands) to check the change in 
the nature of the sample. The samples were filled into the sample holder and placed into the instrument. The test was performed at a voltage of $35 \mathrm{kV}$ and radiation source of $\mathrm{Cu}$-anode. The samples were scanned between $5^{\circ}-70^{\circ}(2$ $\Theta)$ with a scanning rate of $1^{\circ}$ at room temperature. Each spectrum was recorded and compared to evaluate the change in diffraction angle. ${ }^{22}$

\section{In-vitro Release Study}

The drug release from the prepared CTM-CHNPopt and CTM solution (control) was performed by using the dialysis bag. The samples $(5 \mathrm{~mL})$ were filled in a dialysis bag and tied from both ends. The bag was immersed in the release medium (simulated tear fluid, STF), and stirred for $50 \mathrm{rpm}^{23}$ At predetermined time intervals $(1,2,3,4,6,8$, and 12 hours) the released samples $(2 \mathrm{~mL})$ were withdrawn and replaced with fresh release media. The released drug concentration at each time point was analyzed by using a UV-spectrophotometer (Shimadzu 1800 UVSpectrophotometer, Japan) at $210 \mathrm{~nm}$ after appropriate dilution. The in-vitro release data were fitted in a different release kinetic model, ie, zero-order, first-order, Higuchi model, Korsmeyer Peppas, Hixon-Crowell model to check the release mechanism. Regression coefficient $\left(\mathrm{R}^{2}\right)$ was used as a parameter to select the best-fit release kinetic model.

\section{Ex-vivo Permeation Study}

The ex-vivo permeation study of CTM-CHNPopt and CTM-solution was performed on goat cornea. Goat eyeballs were collected from a slaughter house in a sterile beaker and all procedures were performed under aseptic conditions. The eyeballs were washed five times with Phosphate Buffer Saline (PBS) and extra tissue was removed. The cornea was collected from the goat eye and placed into normal saline $(0.9 \% \mathrm{w} / \mathrm{v})$ at $4^{\circ} \mathrm{C}$. The excised cornea was placed between the donor and acceptor compartment of the diffusion cell (active surface area $1.5 \mathrm{~cm}^{2}$ ). The acceptor compartment filled with STF and both samples $(1 \mathrm{~mL})$ were placed in the donor compartment. The study was performed at $37 \pm 0.5^{\circ} \mathrm{C}$ at $50 \mathrm{rpm}$. The permeated aliquots $(1 \mathrm{~mL})$ were withdrawn at a specific time interval and simultaneously replaced with the same volume of fresh STF. The permeated concentration of each sample was estimated by using the previously validated RP-HPLC method. ${ }^{24}$

\section{Bioadhesion Study}

The bioadhesive strength of CTM-CHNPopt was done by using pig mucin. ${ }^{25}$ The pig mucin $(0.05 \mathrm{M})$ suspension was prepared in STF. The placebo and CTM-CHNPopt were incubated with pig mucin $(1 \mathrm{~mL})$ for 30 minutes. The sample was ultracentrifuged using a cooling centrifuge $\left(4^{\circ} \mathrm{C}\right.$, Remi-24, 15,000 rpm). The clear supernatant was separated and quantifies the free mucin by a UVVisible spectrophotometer (Shimadzu, UV-Vis-1800, Tokyo, Japan). The mucoadhesive strength was calculated by the following formula

$$
\begin{aligned}
& \% \text { Bioadhesion strength } \\
& \begin{array}{l}
\text { Initial conc of } \\
\text { pig mucin }
\end{array} \\
& =\frac{\begin{array}{c}
\text { Conc of pig mucin } \\
\text { in supernatant }
\end{array}}{\text { Initial conc of pig mucin }} \\
& \times 100
\end{aligned}
$$

\section{Corneal Hydration Study}

The corneal hydration study was performed to check the hydration of cornea after treatment with CTM-CHNPopt. After the completion of the corneal permeation study, the cornea was removed from the diffusion cell. The cornea weight was taken and termed as wet weight. After weighing the wet cornea was placed into a hot air oven (Thermo scientific, Germany) at $60^{\circ} \mathrm{C}$ for 3 days and again the weight was taken (dry weight). The corneal hydration was calculated by the following equation

$$
\begin{aligned}
& \% \text { Corneal hydration } \\
& =\frac{\text { Wet weight of cornea }- \text { Dry weight of cornea }}{\text { Dry weight of cornea }} \times 100
\end{aligned}
$$

\section{Histopathological Examination}

Histopathological examination of CTM-CHNPopt was done to check the internal damage of the cornea. The study was performed with the cornea used in the ex-vivo permeation study. ${ }^{26}$ The treated cornea removed from the diffusion cell after permeation study and placed into formalin solution $(8 \% \mathrm{v} / \mathrm{v})$. The cornea was washed with alcohol to remove water and fixed with paraffin wax for making the solid block. The prepared solid block was placed in a microtome cutter and a cross-section was cut and stained with haemotoxylin and eosin. ${ }^{27}$ Finally, the slide was examined by using a digital motic microscope (Motic digital Microscope, B3 DMWB, Pal system, Japan) 
at $40 \mathrm{x}$ and the images were compared with the normal saline-treated cornea $(0.9 \% \mathrm{NaCl}$, control).

\section{Isotonicity Evaluation}

Isotonicity of CTM-CHNPopt and normal saline $(0.9 \% \mathrm{w} /$ v) was done on the blood sample. A drop of the test sample was thoroughly mixed with a drop of blood over a glass slide and the thin film was prepared. The film was air-dried and a drop of Leishman's stain was added for staining. The slide was kept aside for a few minutes and the excess dye was removed with water. The slide of each treated sample was examined by a light microscope at 40x. The red blood cell was observed and compared with normal saline for any damage.

\section{Ocular Irritation Study}

This study was performed as a Hen's egg chorioallantoic membrane test (HET-CAM). The fertilized hen egg was procured from the local poultry house and incubated in a rotatory humidified incubator at $37^{\circ} \mathrm{C} / 60 \% \mathrm{RH}$ for 10 days. On the 10th day, the egg was removed from the incubator and tested for the CAM using the slit lamp. The eggshell was broken from the air chamber side and the membrane was carefully removed using sterile forceps. One drop of CTM-CHNPopt, normal saline $(0.9 \% \mathrm{NaCl}$, negative control) and sodium hydroxide $(0.1 \mathrm{M} \mathrm{NaOH}$, positive control) was applied over the CAM and the irritation scores were noted at a different time interval $(0$ minutes, 2 minutes, and 5 minutes). The scoring was done as per the standard scoring system $^{28}$ shown in Table 2.

\section{Antimicrobial Assessment}

An antimicrobial susceptibility study of CTM-CHNPopt and CTM-solution was performed by cup plate method. The sterilized nutrient agar media was prepared and transferred to sterilized Petri plates containing strain (Streptococcus aureus and Pseudomonas aeruginosa) under aseptic conditions. The media was mixed properly for homogeneous distribution of microorganisms and ketp aside for solidification. The well (4-5 $\mathrm{mm}$ size) was made using a sterilized borer and then CTM-CHNPopt, CTMsolution, and normal saline (control) were placed into the well. It was kept in the same conditions for 10 minutes to be absorbed into nutrient media. The plate was further incubated at $37^{\circ} \mathrm{C}$ for 24 hours in an incubator and then the zone of inhibition was measured.

\section{Results and Discussion Optimization}

CTM-CHNPs were prepared and optimized by using three factors and three levels of Box-Behnken design. The design showed a total of 17 formulation runs with the five-center point. The effect of independent variables [Chitosan (A), Tripolyphosphate (B), stirring speed (C)] were evaluated on dependent variables [particle size (Y1) and entrapment efficiency (Y2)]. The result of actual and predicted value with the composition was expressed in Table 1. The data of all experimental runs was fitted into a different model, ie, linear, first, quadratic, and cubic models for determination of a best fit model. The best fit model was found to be the quadratic model and the value for both the responses are shown in Table 3. The lack of fit value of the quadratic model for both the responses were found to be nonsignificant $(P>0.05)$. It revealed that the model was well fitted and less percent variation was observed between actual and predicted value. The higher value of regression coefficient (close to 1), as well as Fisher $(\mathrm{F})$ value than other models, were analyzed by analysis of variance (ANOVA). The ANOVA of the best fit model and statistical regression for all models were analyzed from software, and data are expressed in Table 4. The polynomial equation of the quadratic model of both responses was generated from the software, which shows a significant effect on each response. Each variable has shown the individual and combined effect on the particle size and encapsulation efficiency. The threedimensional plot and contour plot for each response was generated and explained the interaction effect between independent variables (Figure 1A and B). The adequate

Table 2 Standard HET-CAM Score Used to Evaluate Ocular Tolerance

\begin{tabular}{|l|l|l|l|}
\hline S. No. & Effect of Formulation on CAM & Score & Presumption \\
\hline 1 & No visible hemorrhage & 0 & No irritation \\
2 & Observable membrane discoloration & 1 & Mild-irritant \\
3 & Structure cover partially the area of CAM due to membrane discoloration & 2 & Moderate irritant \\
4 & Structure fully cover the area of CAM due to membrane discoloration & 3 & Severe irritant \\
\hline
\end{tabular}


Table 3 Analysis of Variance Data of Each Response for Formulation (CTM-CHTNPs)

\begin{tabular}{|c|c|c|c|}
\hline Model & Source & $\begin{array}{l}\text { Response-I } \\
\text { (Particle } \\
\text { Size, } Y_{1} \text { ) }\end{array}$ & $\begin{array}{l}\text { Response-2 } \\
\text { (Entrapment } \\
\text { Efficiency, } Y_{2} \text { ) }\end{array}$ \\
\hline \multirow[t]{7}{*}{ Quadratic } & \multirow{7}{*}{$\begin{array}{l}\text { Sum of squares } \\
d f \\
\text { Mean square } \\
\text { F-value } \\
\text { P-value, } \\
\text { Prob }>F \\
\text { Remark }\end{array}$} & $36,705.93$ & 2011.95 \\
\hline & & 9 & 9 \\
\hline & & 4078.44 & 223.55 \\
\hline & & 8529.60 & $5|75.7|$ \\
\hline & & $<0.0001$ & $<0.0001$ \\
\hline & & \multirow{2}{*}{\multicolumn{2}{|c|}{ Suggested, significant }} \\
\hline & & & \\
\hline \multicolumn{4}{|c|}{ Lack of Fit } \\
\hline \multirow[t]{7}{*}{ Quadratic } & Sum of squares & 0.8394 & 0.05 \\
\hline & & 3 & 3 \\
\hline & Mean square & 0.28 & 0.017 \\
\hline & F-value & 0.47 & 0.28 \\
\hline & $P$-value, & 0.73 & 0.84 \\
\hline & Prob $>F$ & & \\
\hline & Remark & \multicolumn{2}{|c|}{ Suggested, nonsignificant } \\
\hline \multicolumn{4}{|l|}{ Residual } \\
\hline \multirow[t]{3}{*}{ Quadratic } & Sum of squares & 3.35 & 0.31 \\
\hline & & 7 & 7 \\
\hline & Mean square & 0.48 & 0.04 \\
\hline
\end{tabular}

precision quadratic model of both responses was found to be greater than four, which evealed that the model is well fitted.

\section{Effect of Formulation Variable on Particle Size $(\mathrm{YI})$}

The particle size of all 17 formulations was found in the range of $102.2 \mathrm{~nm}(\mathrm{~F} 12)$ to $283.7 \mathrm{~nm}(\mathrm{~F} 6)$. The 3D and contour plot (Figure 1A) were expressed to evaluate the individual and combined effect of formulation variable.
The model F-value is 8529.6, which revealed that the model is significant $(P<0.05)$. The model term $\mathrm{A}, \mathrm{B}, \mathrm{C}$, $\mathrm{AB}, \mathrm{AC}, \mathrm{BC}, \mathrm{A}^{2}, \mathrm{~B}^{2}$, and $\mathrm{C}^{2}$ are significant $(P<0.05)$ and have a direct influence on the particle size. The lack of fit was found to be nonsignificant $(P>0.05)$, which is good for the formulation model (Table 3). The second order of polynomial equation of the quadratic model for response $1(\mathrm{Y} 1)$ is given as:

Particle size $\left(\mathrm{Y}_{1}\right)=+154.11+50.81 \mathrm{~A}-15.39 \mathrm{~B}-32.69 \mathrm{C}-$ 14.73AB-4.89AC-0.86BC+26.03 $\mathrm{A}^{2}-14.45 \mathrm{~B}^{2}+15.24 \mathrm{C}^{2}$

Where $\mathrm{A}, \mathrm{B}$, and $\mathrm{C}$ are independent variables and $\mathrm{AB}$, $\mathrm{AC}$, and $\mathrm{BC}$ are the interaction terms of an independent variable. The positive and negative signs represent the positive and negative effects on the response. The polynomial equation showed an increase in $\mathrm{CH}$ (A) concentration led to an increase in particle size. The increase in particle size takes place due to an increase in the viscosity of $\mathrm{CH}$ solution. The conductivity decreases and no complete interand intramolecular crosslinking take place with STPP. ${ }^{29,30}$ The STPP (B) showed the antagonistic effect on particle size, the particle size decreased with the increasing STPP concentration. The higher crosslinking takes place between $\mathrm{PO}_{4}{ }^{-}$(STPP) and $\mathrm{NH}_{3}{ }^{+}(\mathrm{CH})$. At high STPP concentration, the particle size increases and the reduction of surface charge takes place due to more $\mathrm{PO}_{4}{ }^{-}$of STPP present as compared to $\mathrm{NH}_{3}{ }^{+}$and deposited on the surface of NPs. ${ }^{31}$

The stirring speed (C) showed a negative and more prominent effect on particle size. On increasing the stirring speed (C) the particle size decreased. It accelerates the mixing of STPP dispersion into the $\mathrm{CH}$ solution, leading to an increase in the shear force and thereby breakdown of NPs takes place. ${ }^{32}$ On other hand, the combined effect of CH and STPP (A and B) showed a more prominent negative effect on particle size than $\mathrm{CH}$ and stirring speed (AC)

Table 4 Statistical Summary Used Design for the Formulation (CTM-CHTNPs)

\begin{tabular}{|c|c|c|c|c|c|}
\hline \multicolumn{6}{|c|}{ Response-I (Particle Size, $Y_{1}$ ) } \\
\hline Source & R-Squared & Adjusted $\mathbf{R}^{2}$ & Predicted $\mathbf{R}^{2}$ & SD & Remark \\
\hline Linear & 0.847 & 0.811 & 0.701 & 20.78 & - \\
\hline $2 \mathrm{FI}$ & 0.873 & 0.797 & 0.436 & 21.56 & - \\
\hline Quadratic & 0.999 & 0.999 & 0.999 & 0.69 & Suggested \\
\hline \multicolumn{6}{|c|}{ Response-2 (Particle size, $\mathbf{Y}_{2}$ ) } \\
\hline Linear & 0.884 & 0.857 & 0.759 & 4.23 & - \\
\hline $2 \mathrm{FI}$ & 0.988 & 0.982 & 0.951 & 1.49 & - \\
\hline Quadratic & 0.999 & 0.999 & 0.999 & 0.21 & Suggested \\
\hline
\end{tabular}



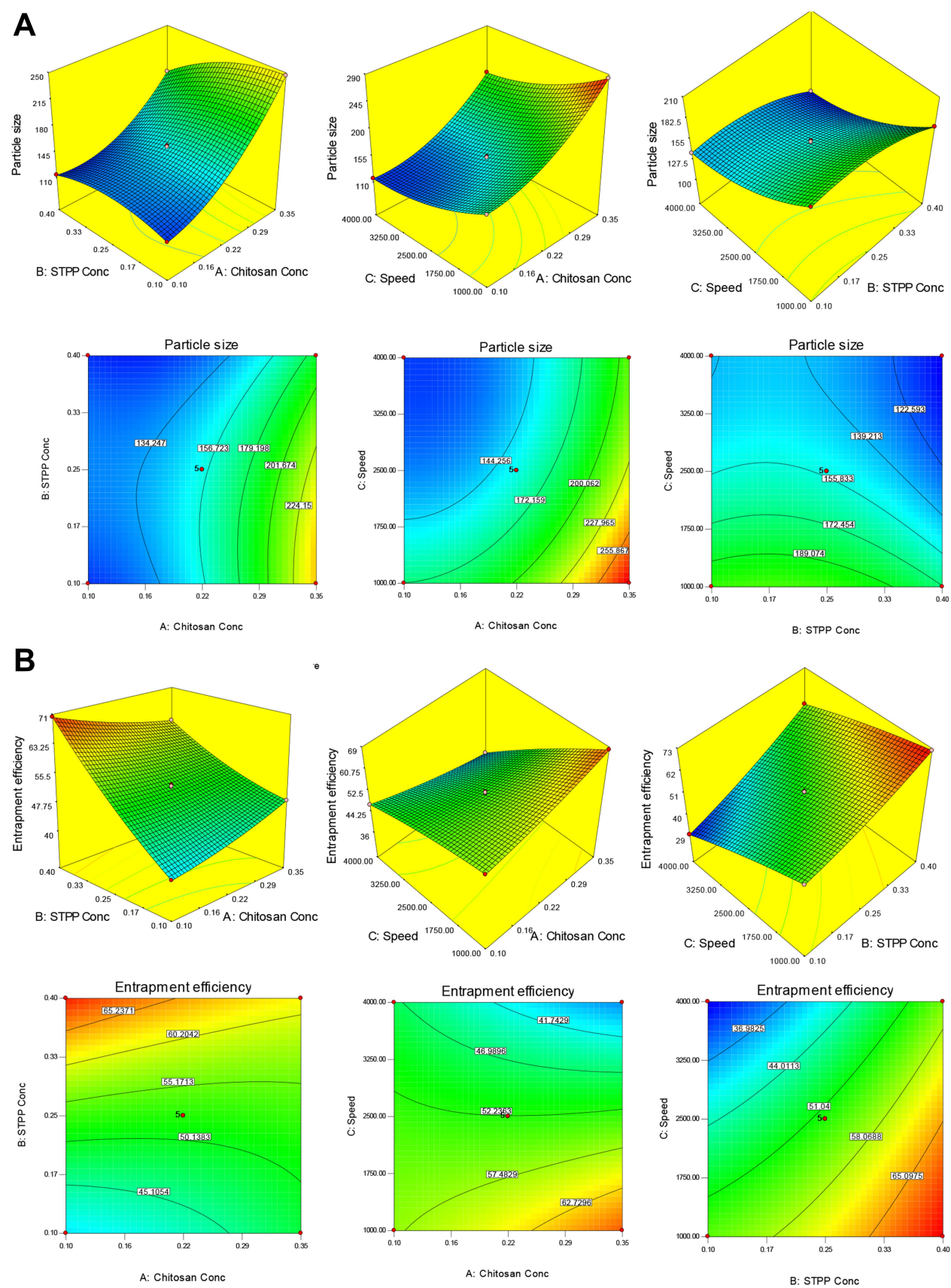

Figure I (A) 3D response surface plot and contour plot showing the effect of independent variables on particle size $\left(X_{1}\right)$. (B) 3D response surface plot and contour plot showing the effect of independent variables on entrapment efficiency $\left(X_{2}\right)$.

as well as STPP and stirring speed (BC). As the concentration of $\mathrm{CH}$ and STPP simultaneously increases the particle size decreases. The more complex inter- and intramolecular gelation takes place between $\mathrm{NH}_{3}{ }^{+} / \mathrm{PO}^{-.33,34}$ The developed formulation was evaluated for a different kinetic model and showed a quadratic model as best fit because of the $\mathrm{R}^{2}$ close to unity as compared to another model (Table 4). The adequate precision was 335.25 (>4) and a predicted $\mathrm{R}^{2}$ of 0.999 is reasonable agreement with an adjusted $\mathrm{R}^{2}$ of 0.999 revealing that good signal for the model.

\section{Effect of Formulation Variable on Entrapment Efficiency $\left(\mathrm{Y}_{2}\right)$}

The prepared formulation showed the \%EE in the range of $30.1 \%$ (F11) to $70.33 \%$ (F3) as shown in Table 1. The actual and predicted values were closer to each other and it shows the closeness of the result data. The $3 \mathrm{D}$ and contour 
plot (Figure 1B) expressed to assess the individual and combined effect of formulation variables. The lack of fit suggested nonsignificant value $(P>0.05)$, which is good for the formulation model (Table 3 ). The polynomial equation and Figure 1B were used to interpret the effect of formulation variables on entrapment efficiency $\left(\mathrm{Y}_{2}\right)$ :

Entrapment efficiency $\left(\mathrm{Y}_{2}\right)=+52.31-3.056 \mathrm{~A}+10.81 \mathrm{~B}-$ $10.27 \mathrm{C}-4.28 \mathrm{AB}-5.47 \mathrm{AC}+2.08 \mathrm{BC}+0.99 \mathrm{~A}^{2}+1.82 \mathrm{~B}^{2}-1.01 \mathrm{C}^{2}$

where $\mathrm{A}, \mathrm{B}$, and $\mathrm{C}$ are independent variables $(\mathrm{CH}$, STPP, and stirring speed), and $\mathrm{AB}, \mathrm{AC}$, and $\mathrm{BC}$ combined variables. The positive and negative sign were used to express the synergistic and antagonistic effect of variables over the response. The polynomial equation showed that CH (A) has a less prominent effect than STPP (B) and stirring speed (C). It was observed that as $\mathrm{CH}$ concentration (A) increases the entrapment efficiency decrease due to the $\mathrm{CH}$ viscosity. At high viscosity, the lesser interaction between $\mathrm{CH}$ and STPP $\left(\mathrm{NH}_{3}{ }^{+} / \mathrm{PO}_{4}{ }^{-}\right)$takes place and leads to low drug entrapment. The increase in $\mathrm{CH}$ concentration leads to hindrance in the movement of rivastigmine and rotigotine towards the $\mathrm{CH}$ chain. ${ }^{33,35}$ STPP exhibited a positive effect on entrapment efficiency. The increase in STPP concentration gives higher CTM entrapment. At higher phosphate ion present for gelling of protonated ion of $\mathrm{CH}\left(\mathrm{NH}_{3}{ }^{+}\right)$gives a high amount of drug diffused in NPs during crosslinking. At a high concentration of STPP, the high entrapment efficiency of dorzolamide was found in CHNPs. ${ }^{36}$ The stirring speed has a negative effect on EE but less prominent effect than STPP. As the stirring speed increases the shear force increases and break down of NPs takes place as well as leaching of the drug from the polymer matrix take place, resulting in decreased EE. ${ }^{35}$ From the ANOVA calculation the F-value and regression coefficient $\left(\mathrm{R}^{2}\right)$ were found to be maximum $(\mathrm{F}=5175.7$, $\left.\mathrm{R}^{2}=0.999\right)$ for the quadratic model than other models (linear, first-order, and cubic), indicating that the quadratic is significant $(P<0.0001)$ and found best-fit model. The predicted $\mathrm{R}^{2}$ is 0.999 and is in rational concurrence with adjusted $\mathrm{R}^{2}$ (0.999) (Table 4). The lack of fit was found to be nonsignificant $(P<0.05)$, and there was less variation found between the actual and predicted value of the response. Adequate precision is greater than 4 (264.6) and indicated that the model has an adequate signal.

\section{Point Prediction Optimization}

The point prediction optimization was employed to select the optimum composition of optimized NPs (CTMCHNPopt). The optimized composition $\mathrm{CH}(0.22 \% \mathrm{w} / \mathrm{v})$,
STPP $(0.25 \% \mathrm{w} / \mathrm{v})$, and stirring speed $(2500 \mathrm{rpm})$ showed the best result of low size and high EE. The composition showed the actual particle size of $152 \pm 5 \mathrm{~nm}$ and entrapment efficiency of $53.05 \pm 3.32 \%$. The predicted result of particle size and encapsulation efficiency were found from the software and found to be $154.11 \mathrm{~nm}$ and $52.31 \%$. The actual result was found to be very close to the predicted result. The percent error between observed and predicted values was found to be $-1.16 \%$ for particle size and $+1.41 \%$ for entrapment efficiency. The result of the actual and predicted value for the particle size and entrapment efficiency is depicted in Figure 2.

\section{Particle Characterization}

The particle size, PDI, and zeta potential of CTMCHNPopt were found to be $152 \pm 5 \mathrm{~nm}, 0.125 \pm 0.02$, and $+35.24 \mathrm{mV}$, respectively. The particle size was found to be within the acceptable size range. The particle size $(>1 \mu \mathrm{m})$ may potentially cause ocular irritation. ${ }^{37}$ The low PDI value revealed a homogenous distribution of particle and also indicates that NPs dispersion is stable as well as nonaggregated. The positive zeta potential value $(+35.24 \mathrm{mV})$ indicates that the formulation was stable and disaggregated to each other. The positive sign of NPs is a good indicator that the chitosan was present at the external interface of the prepared formulations. TEM image was depicted in Figure 3 and the electron microscope image confirmed the formation of spherical shape particles with uniform distribution.

\section{Thermal Evaluation}

The DSC study was performed to check the polymorphic transition of the drug CTM after encapsulation into NPs. The study was performed with CTM, CH, and CTM-CHNPopt, and their thermogram is shown in Figures $4 \mathrm{~A}-\mathrm{C}$. The thermogram of CTM showed the intense characteristic endothermic peak at its melting point $\left(230.5^{\circ} \mathrm{C}\right)$ which revealed the crystalline nature (Figure 4A). $\mathrm{CH}$ showed two characteristic peaks, a first endothermic broad peak at $72.3^{\circ} \mathrm{C}$ due to evaporation of water molecules and a second exothermic peak due to degradation $\left(270^{\circ} \mathrm{C}\right)$ (Figure $\left.4 \mathrm{~B}\right)$. There was no characteristic peak of CTM observed in the thermogram of CTMCHNPopt. Only the peaks at $61.5^{\circ} \mathrm{C}$ and $260^{\circ} \mathrm{C}$ were observed (Figure 4C), which revealed that drug was present in molecular dispersion form in NPs matrix or there was a loss of crystallinity. A similar observation was reported by the researcher in their study. ${ }^{38,39}$ Nair et al ${ }^{39}$ reported that no 


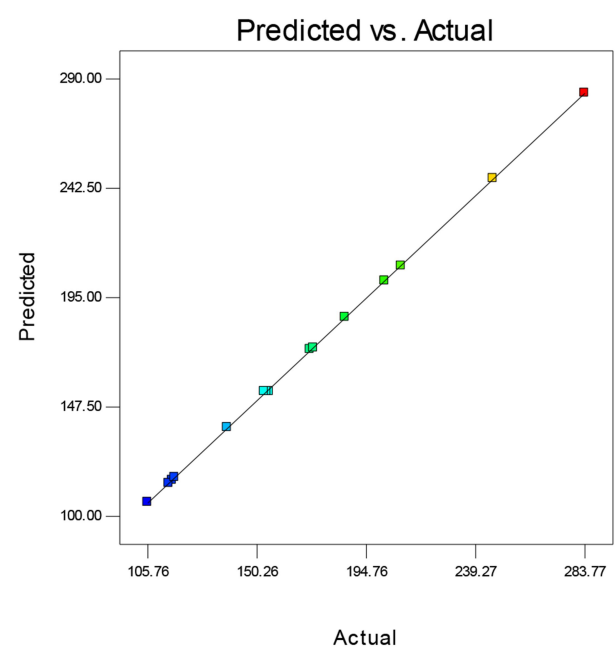

A: Particle size

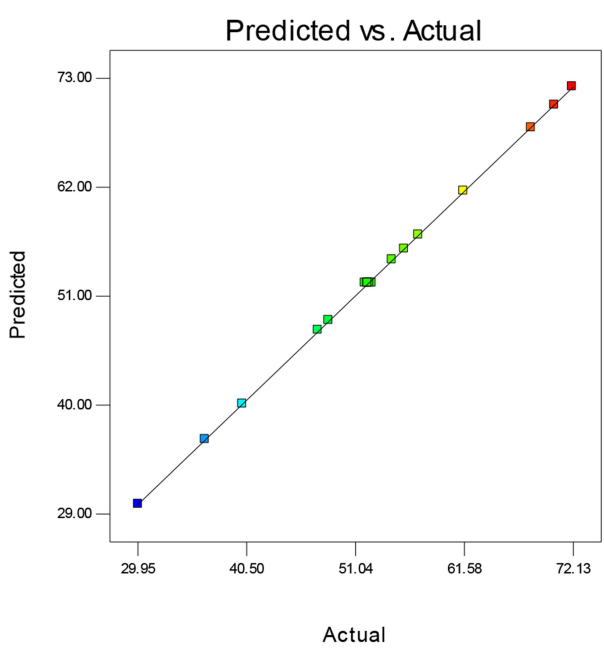

B: Entrapment efficiency

Figure 2 Actual and predicted response of independent variables on (A) particle size (nm), (B) entrapment efficiency (\%).

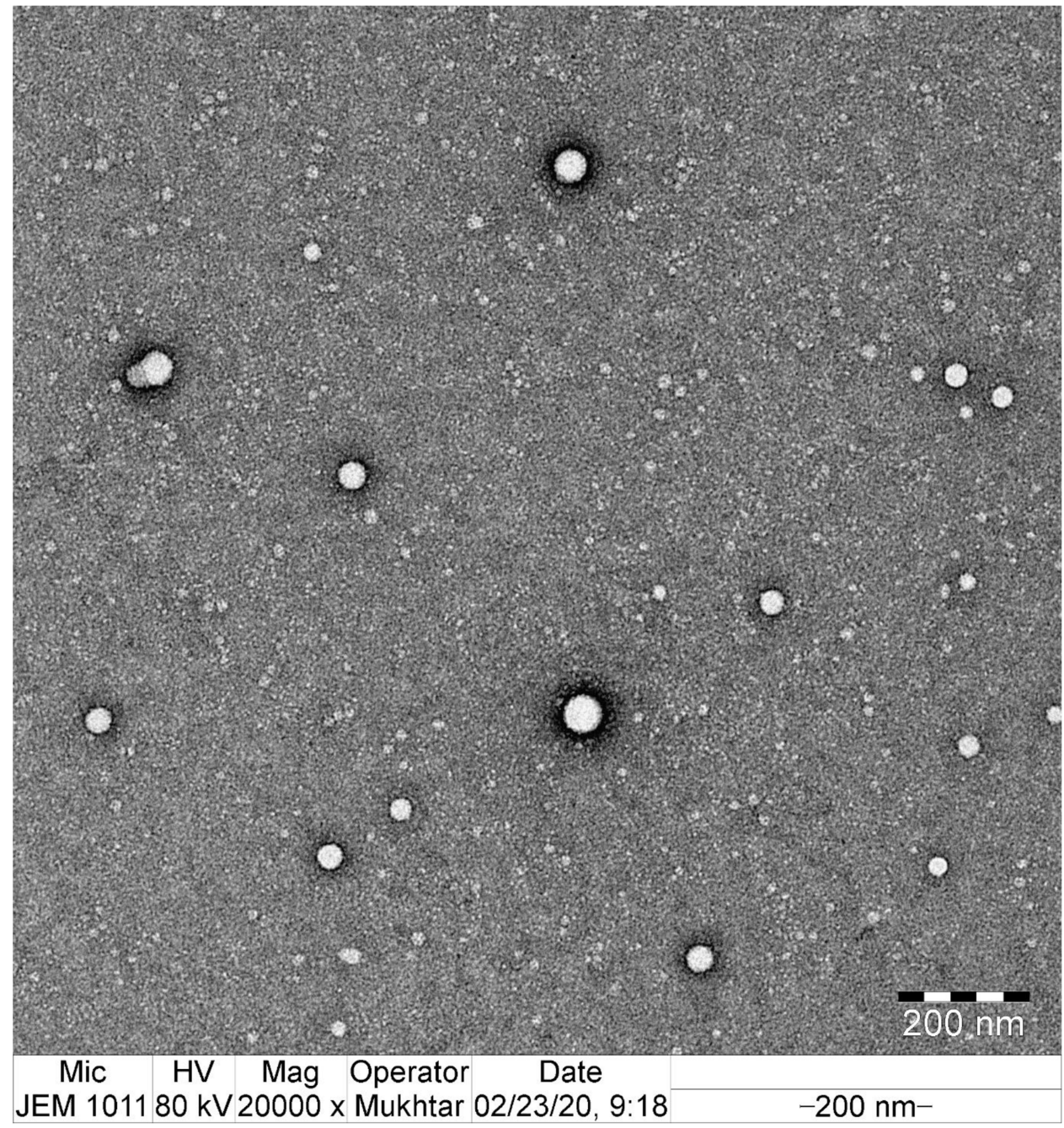

Figure 3 TEM image of optimized clarithromycin nanoparticle (CTM-CHNPopt). 


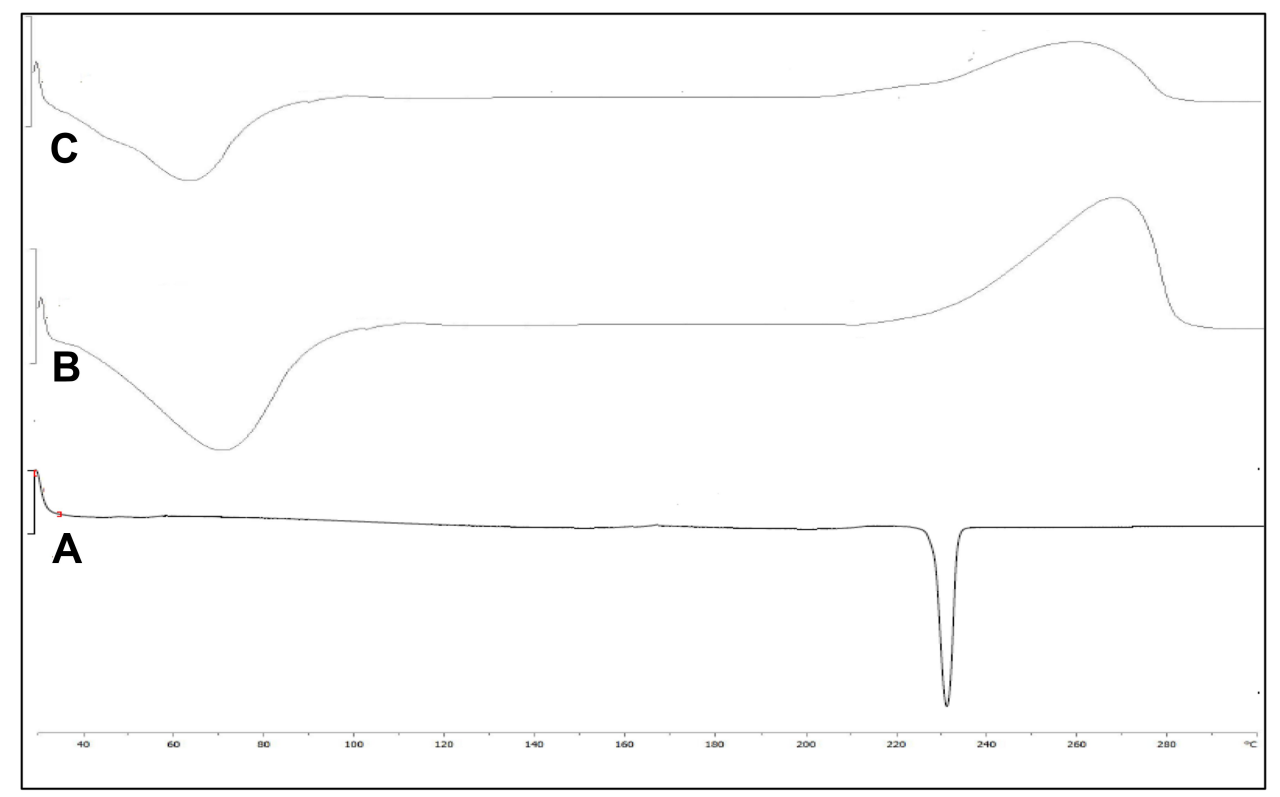

Figure 4 DSC thermogram of (A) clarithromycin, (B) chitosan, (C) optimized clarithromycin nanoparticles (CTM-CHNPopt).

curcumin peak was observed due to molecular dispersion in a polymer matrix.

\section{X-Ray Diffraction Study}

The study was performed to evaluate the crystal lattice arrangement at the atomic level of each tested sample. Figures $5 \mathrm{~A}-\mathrm{C}$ represent the diffraction pattern of CTM, $\mathrm{CH}$, and CTM-CHNPopt. CTM exhibited an intense characteristic peak at diffraction $10^{\circ}, 11.2^{\circ}, 13.27^{\circ}, 15.95^{\circ}$, $19.10^{\circ}, 20.23^{\circ}, 22.13^{\circ}, 23.24^{\circ}$, and $25^{\circ}$ at $2 \theta$ of diffraction angle, confirming its crystalline nature. However, $\mathrm{CH}$ showed the prominent wide diffraction peak at $9.5^{\circ}$ and $20^{\circ}$ at $2 \theta$ angle. The single crystal of chitosan did not contain water even if grown in an aqueous environment. It can be explained by the high crystal growth temperature. $^{40}$ There was no characteristic diffraction peak observed for CTM in a CTM-CHNPopt diffractogram. This result revealed the change in characteristic diffraction peak may be due to the structural modification and conversion of crystalline to amorphous form. CTM is

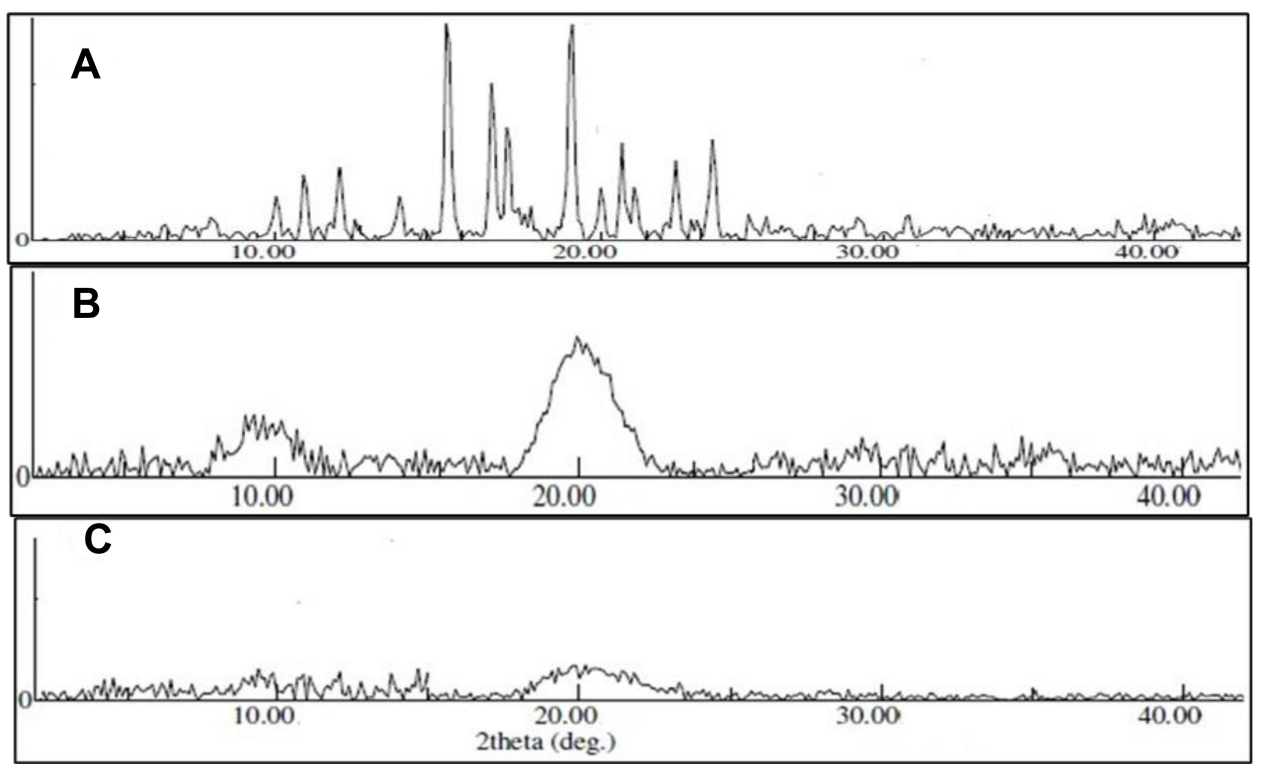

Figure 5 XRD image of (A) clarithromycin, (B) chitosan, (C) optimized clarithromycin nanoparticles (CTM-CHNPopt). 
completely solubilized and entrapped in the used polymer chitosan and TPP linkage. ${ }^{41}$

\section{In-vitro Release Study}

In-vitro release study data of CTM-CHNPopt and CTM-solution are depicted in Figure 6. The CTM-CHNPopt showed a dual release pattern, ie, initial burst release $(25.8 \pm 2.3 \%$ in 1 hour) and after that slow and sustained release was observed ( $82.9 \pm 3.9 \%$ in 12 hours). CTM-solution showed about 99.9 $\pm 4.7 \%$ drug release in 3 hours and CTM-CHNPopt released $38.6 \pm 3.9$ in the same time. The initial burst release was found due to the release of CTM from the surface of NPs. The slow and prolonged CTM release was achieved due to the slower diffusion of the drug from the polymer core. The release data of CTM-CHNPopt formulation was fitted into a difference kinetic model. The order of regression coefficient is Korsmeyer-Peppas model $\left(r^{2}=0.996\right)>$ first order $\left(r^{2}=0.995\right)$ $>$ Higuchi $\quad\left(r^{2}=0.993\right)>$ Hixon-Crowell model $\quad\left(r^{2}=0.989\right)$ >zero-order $\left(r^{2}=0.952\right)$. The highest regression coefficient was found for the Korsmeyer-Peppas model and suggested as the best fit model. The release exponent of the KorsmeyerPeppas model is $\leq 0.5$ (0.474), demonstrating that Fickian diffusion is the controlling factor in the drug release process, ie, CTM release rate into release medium depends upon the molecular diffusion CHNPs system. ${ }^{42}$

\section{Permeation Study}

Figure 7 expressed the ex-vivo corneal permeation study results of CTM-CHNPopt and CTM-solution. There was a significant difference in permeation observed. The sample CTM-CHNPopt showed significant $(P<0.05)$ enhanced permeation $\left(194.21 \mu \mathrm{g} / \mathrm{cm}^{2}, 77.63 \%\right)$ than CTM-solution $\left(71.56 \mu \mathrm{g} / \mathrm{cm}^{2}, 28.62 \%\right)$. There was a 2.71 -fold enhancement seen in permeation for CTM-CHNPopt over the CTM-solution. Further, the flux was also calculated for CTM-CHNPopt and CTM-solution, and the result showed $30.93 \mu \mathrm{g} / \mathrm{cm}^{2} / \mathrm{h}$, and $11.83 \mu \mathrm{g} / \mathrm{cm}^{2} / \mathrm{h}$, respectively. The higher permeation and flux were achieved due to the presence of $\mathrm{CH}$ as a polymer and nano-sized particle. It acts as a permeation enhancer and has the bioadhesive property as well as having the cationic charge on NPs. The cationic charge of $\mathrm{CH}$ binds with an anionic charge of corneal mucin, thereby enhancing the precorneal residence time as well as permeation. ${ }^{43}$ The enhanced drug permeation was achieved due to the higher retention of NPs at the corneal surface due to the mucoadhesive nature of $\mathrm{CH}$. The protonated amino group of $\mathrm{CH}$ takes ionic interaction with the negative charge of corneal mucin. ${ }^{44}$ The endocytic uptake of NPs was as well as improved transport of released drug via paracellular route due to widening of the tight junction in the presence of $\mathrm{CH}^{45}$

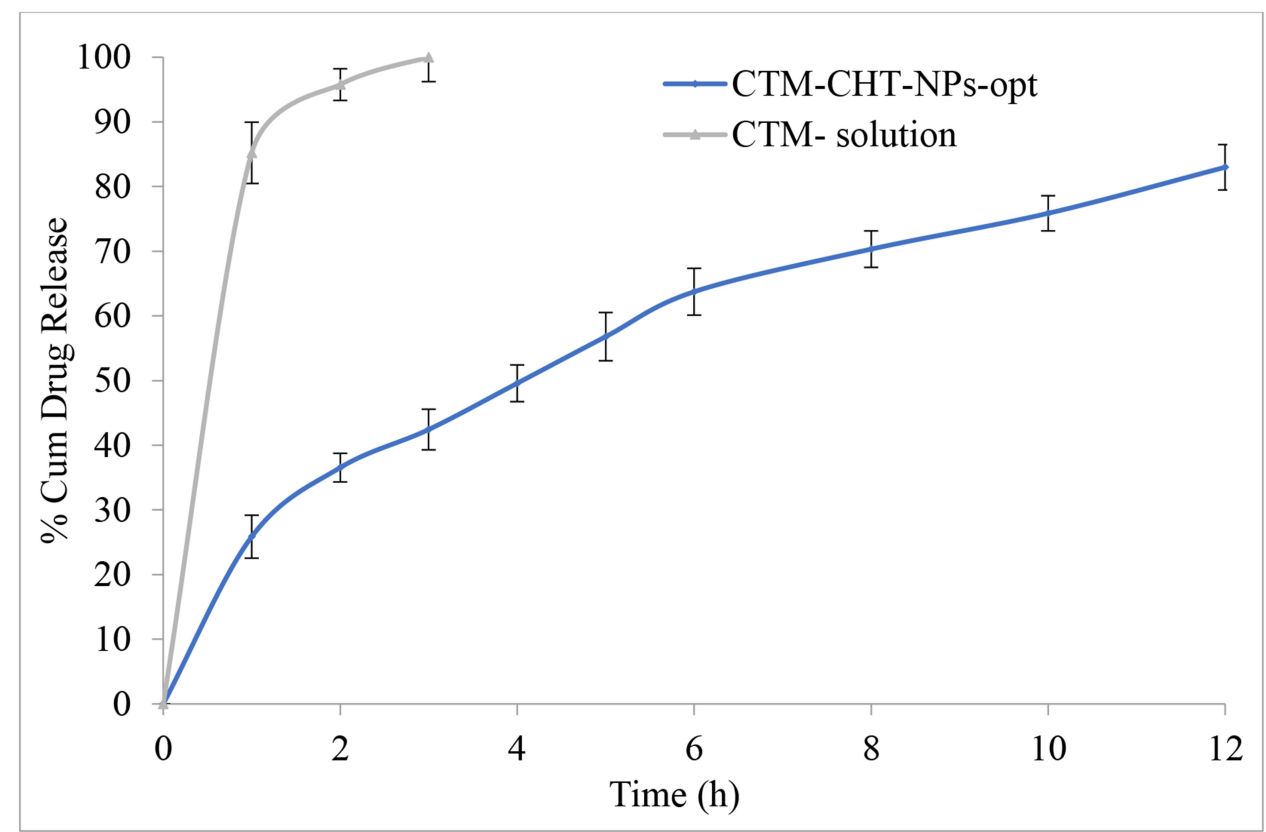

Figure 6 Comparative drug release profile of optimized clarithromycin nanoparticles (CTM-CHNPopt) and clarithromycin solution. Values are presented as mean \pm SD with triplicates. 


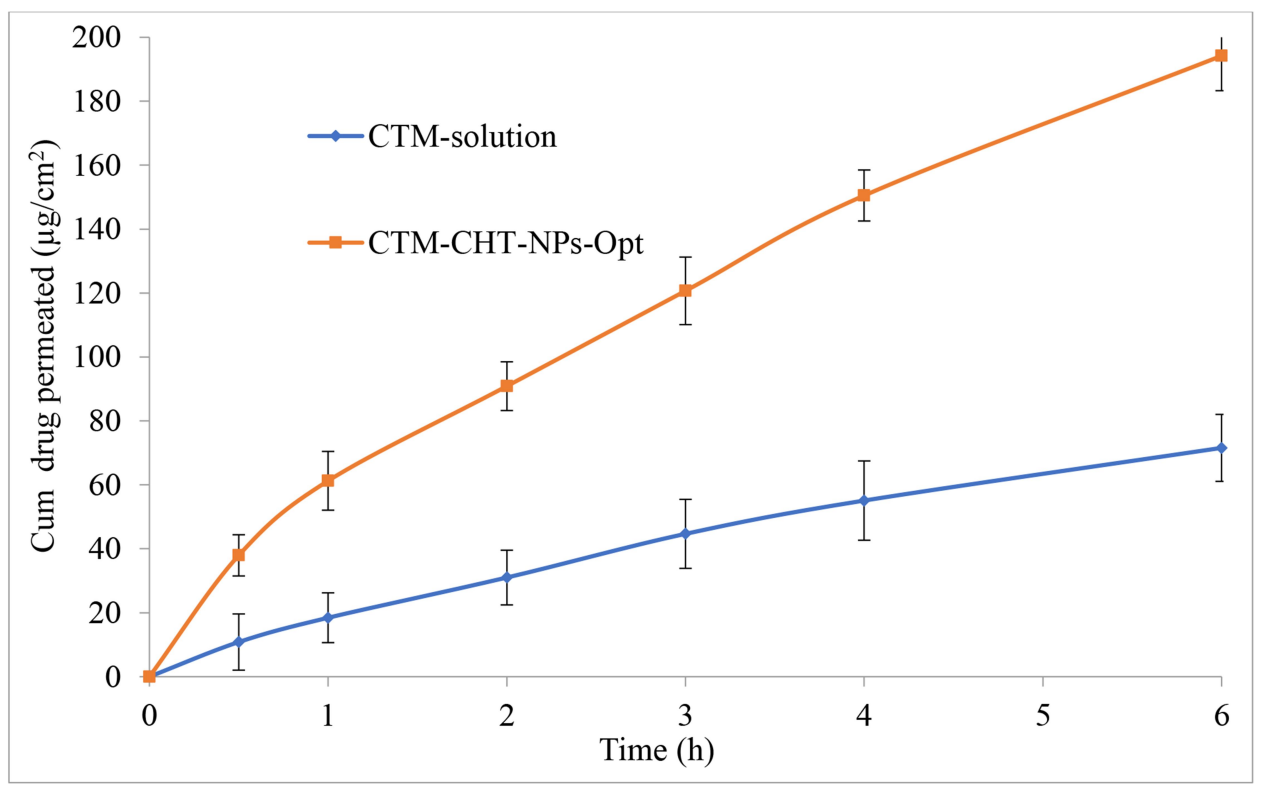

Figure 7 Comparative drug permeation profile of optimized clarithromycin nanoparticles (CTM-CHNPopt) and clarithromycin solution. Values are presented as mean \pm SD with triplicates.

\section{Bioadhesion Study}

Bioadhesion study was performed for the developed CTMCHNPopt formulation and the result showed excellent bioadhesion properties, ie, $89.86 \pm 3.6 \%$. The high bioadhesion is due to the mucoadhesive nature of $\mathrm{CH}$ and the positive zeta potential value. ${ }^{46}$ The positive value of zeta potential denotes the positive surface of NPs and has an important role in the mucoadhesion. The positive charged chitosan NPs can easily interact with the negatively charged mucin sialic group. ${ }^{47}$ The enhanced interaction between these two leads to the formation of stable NPs which might be indicative of a promising delivery system. This result predicts that CHNPs will bind with corneal mucin.

\section{Corneal Hydration Study}

The ocular damage can be evaluated by the hydration test. CTM-CHNPopt exposed cornea showed a significant hydration level and the result found was between the acceptable limit of $76-80 \%$ (ie, $79.04 \pm 1.78 \%$ ). ${ }^{48}$ This value revealed that CTM-CHNPopt showed an acceptable hydration limit and did not produce any harm to the corneal tissue (epithelium or endothelium). The result was further confirmed by histopathological examination of cornea.

\section{Histopathological Examination}

Histopathology study was done to evaluate the internal damage of the cornea after treatment with CTMCHNPopt. The treated cornea with CTM-CHNPopt and sodium chloride $(0.9 \% \mathrm{NaCl}$, control) was compared (figure not shown). There was no morphological or histological alteration in the cornea observed. The epithelium, Bowman's membrane, and stroma of cornea and the cells were found intact, similar to the control-treated sample. The morphology of the cornea was also well maintained. ${ }^{11}$ From the study, it was confirmed that CHNPs is non-toxic and safe for ophthalmic application. The histopathology study results advocated the safe use of polymeric NPs.

\section{Isotonicity Evaluation}

The isotonicity evaluation was performed to check the compatibility between CTM-CHNPopt and blood. Figures 8A and $\mathrm{B}$ are shown to evaluate the isotonicity with CTMCHNPopt and normal saline (control). There was negligible haemolysis and RBC cell damage was observed for CTMCHNPopt after incubation with erythrocytes (Figure 8A). The result was found to be similar to the normal saline (Figure 8B) treated blood. This revealed that CTMCHNPopt is hemocompatible and safe to use for further invivo applications.

\section{Ocular Irritation}

The test was performed to check the ocular tolerance study by comparing the result between CTM-CHNPopt, normal saline (negative control), and $0.1 \mathrm{M} \mathrm{NaOH}$ (positive control) treated fertilized hen egg. The scores were taken as per the standard scale shown in Table 2 and the images 


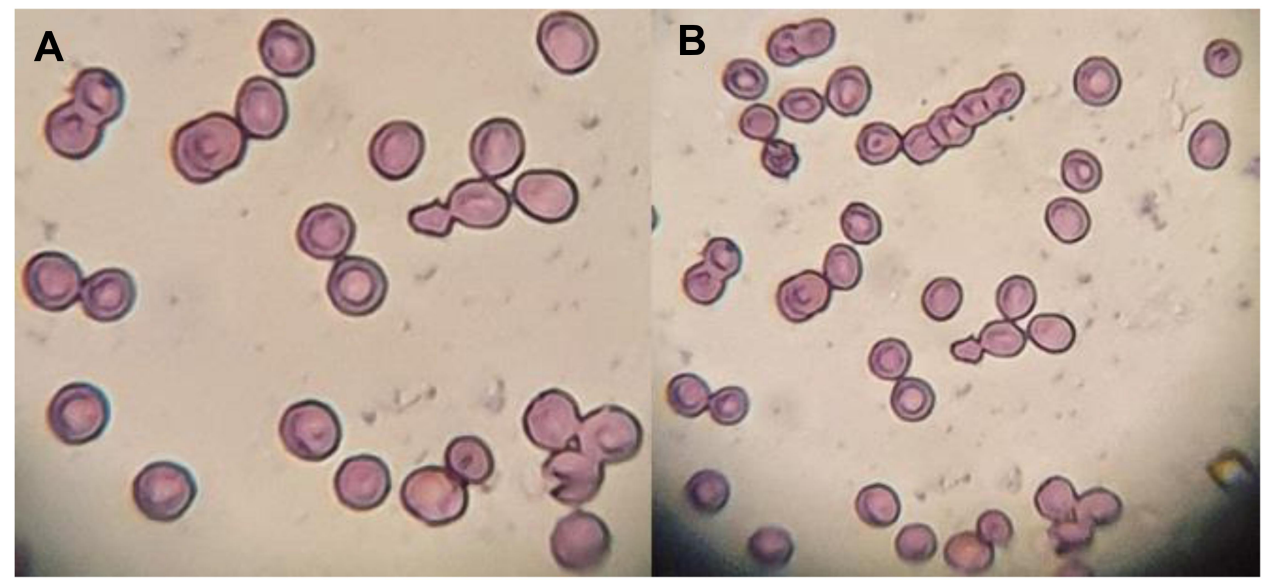

Figure 8 Comparative isotonicity image (A) CTM-CHNPopt, (B) normal saline (control).

were shown in Figure 9. The mean score for CTMCHNPopt and the normal saline-treated group showed zero score after 5 minutes of treatment, whereas the 0.1 $\mathrm{NaOH}$ (positive control) treated group showed a mean score of 14.5. CTM-CHNPopt and normal saline (negative control) treated group showed no damage to the blood vessels and also no rupture was observed (non-irritant). There was significant damage to the blood vessels observed with the positive control-treated group and categorized as an irritant group. From the results, we concluded that the developed nano-formulation is safe for ocular administration. Similar findings were reported in the published literature of dorzolamide NPs-gel ${ }^{36}$ and rosmarinic acid NPs. ${ }^{49}$

\section{Antimicrobial Assessment}

The comparative antimicrobial study between CTM-CHNPopt and CTM-solution $(0.25 \% \mathrm{w} / \mathrm{v})$ was performed against $S$. aureus and $P$. aeruginosa microorganisms. The sample CTMCHNPopt treated Petri dish showed the zone of inhibition (ZOI) of $26.5 \pm 1.25 \mathrm{~mm}$ against $S$. aureus and 24.25 $\pm 0.75 \mathrm{~mm}$ against $P$. aeruginosa. In the case of CTM-solution, the ZOI was found to be $19.25 \pm 1.85 \mathrm{~mm}$ against $S$. aureus and $15.75 \pm 1.67 \mathrm{~mm}$ against $P$. aeruginosa. The prepared formulation CTM-CHNPopt showed significant $(P<0.05)$ higher susceptibility (1.4-fold and 1.53-fold) than CTM-solution. There are many pieces of literature reporting the antimicrobial activity of $\mathrm{CH}$, and it also possesses hemostatic properties that enhance the blood clotting. ${ }^{16}$ The enhanced antibacterial activity of the CHNPs is due to the nano size, spherical particles structure and high surface energy. They will get a large surface area to act on the cell wall of microorganisms. The cationic CHNPs interact with the negatively charges bacteria surface to a greater extent and disrupt the membrane and produce leakage of the intracellular compound, leading to the death of microorganisms. The interaction of $\mathrm{CH}$ with the outer membrane may contribute to the enhanced antibacterial activities. ${ }^{18}$

\section{Conclusions}

CTM-CHNPs were successfully prepared by ionotropic gelation method and optimized by Box-Behnken design using three factors and two levels. CTM-CHNPopt has shown the particle

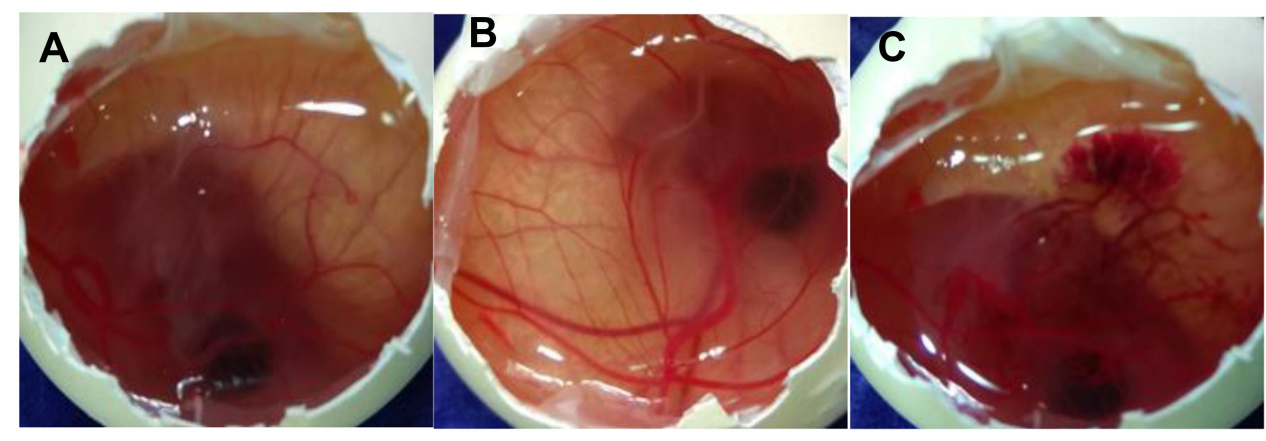

Figure 9 HET-CAM images (A) CTM-CHNPopt, (B) normal saline (negative control), (C) $0.1 \mathrm{M} \mathrm{NaOH}$ (positive control) (C). 
size to be less than $200 \mathrm{~nm}$, which is ideal for ocular delivery. The prepared formulation showed positive zeta potential, indicating the particles are non-aggregated and spherical. The thermal and $\mathrm{x}$-ray diffraction analysis indicated that CTM was completely dispersed in the polymer matrix. The sustained release profile with significantly enhanced corneal permeation $(P<0.05)$ was achieved in comparison to CTM-solution. The hydration, histopathology, and HET-CAM test revealed there was no sign of ocular damage observed on excised goat cornea. It also exhibited significant $(P<0.05)$ higher antibacterial susceptibility than CTM-solution. The finding concluded that CTM-CHNPs can be used as an antibacterial drug delivery system with greater precorneal residence time and increased patient compliance by reducing the dose frequency.

\section{Funding}

This work was funded by the Deanship of Scientific Research at Princess Nourah Bint Abdulrahman University through the Fast-track Research Funding Program.

\section{Disclosure}

The authors report no conflicts of interest for this work.

\section{References}

1. Khare A, Singh I, Pawar P, Grover K. Design and evaluation of voriconazole loaded solid lipid nanoparticles for ophthalmic application. J Drug Deliv. 2016;6590361:11.

2. Achouri D, Alhanout K, Piccerelle P, Andrieu V. Recent advances in ocular drug delivery. Drug Dev Ind Pharm. 2013;39(11):1599-1617. doi:10.3109/03639045.2012.736515

3. Ilka R, Mohseni M, Kianirad M, Naseripour M, Ashtari K, Mehravi B. Nanogel-based natural polymers as smart carriers for the controlled delivery of Timolol Maleate through the cornea for glaucoma. Int $J$ Biol Macromol. 2018;109:955-962. doi:10.1016/j.ijbiomac. 2017.11.090

4. Mittal N, Kaur G. Investigations on polymeric nanoparticles for ocular delivery. Adv Pol Tech. 2019;14.

5. Tan G, Yu S, Pan H, et al. Bioadhesive chitosan-loaded liposomes: a more efficient and higher permeable ocular delivery platform for timolol maleate. Int $J$ Biol Macromol. 2017;94:355-363. doi:10.1016/j.ijbiomac.2016.10.035

6. Ameeduzzafar AJ, Khan N, Ali A, Ali A. Development and optimization of carteolol loaded carboxymethyl tamarind kernel polysaccharide nanoparticles for ophthalmic delivery: box-behnken design, in vitro, ex vivo assessment. Sci Adv Mater. 2014;6(1):63-75. doi:10.1166/ sam.2014.1681

7. Katara R, Sachdeva S, Majumdar DK. Design, characterization, and evaluation of aceclofenac-loaded eudragit RS 100 nanoparticulate system for ocular delivery. Pharm Dev Technol. 2019;24(3):368-379. doi:10.1080/10837450.2018.1486424

8. Sohail R, Abbas SR. Evaluation of amygdalin-loaded alginate-chitosan nanoparticles as biocompatible drug delivery carriers for anticancerous efficacy. Int $J$ Biol Macromol. 2020;153:36-45. doi:10.1016/j. ijbiomac.2020.02.191
9. Dubey V, Mohan P, Dangi JS, Kesavan K. Brinzolamide loaded chitosan-pectin mucoadhesive nanocapsules for management of glaucoma: formulation, characterization and pharmacodynamic study. Int J Biol Macromol. 2020;152:1224-1232. doi:10.1016/j.ijbiomac.2019.10.219

10. Ameeduzzafar SS, Abbas Bukhari SN, Ahmad J, Ali A, Ali A. Formulation and optimization of levofloxacin loaded chitosan nanoparticle for ocular delivery: in-vitro characterization, ocular tolerance and antibacterial activity. Int J Biol Macromol. 2018;108:650-659. doi:10.1016/j.ijbiomac.2017.11.170

11. Mittal N, Kaur G. Leucaena Leucocephala (Lam.) galactomannan nanoparticles: optimization and characterization for ocular delivery in glaucoma treatment. Int J Biol Macromol. 2019;139:1252-1262. doi:10.1016/j.ijbiomac.2019.08.107

12. Paliwal R, Paliwal SR, Sulakhiya K, Kurmi BD, Kenwat R, Mamgain A. Chitosan-based nanocarriers for ophthalmic applications. Polysaccharide Carriers Drug Deliv. 2019;79-104.

13. Younes I, Rinaudo M. Chitin and chitosan preparation from marine sources. Structure, properties and applications. Mar Drugs. 2015;13 (3):1133-1174. doi:10.3390/md13031133

14. Duxfield L, Sultana R, Wang R, et al. Development of gatifloxacinloaded cationic polymeric nanoparticles for ocular drug delivery. Pharm Dev Technol. 2016;21(2):172-179. doi:10.3109/10837450. 2015.1091839.

15. Dubashynskaya N, Poshina D, Raik S, Urtti A, Skorik YA. Polysaccharides in ocular drug delivery. Pharmaceutics. 2020;12:22. doi:10.3390/pharmaceutics12010022.

16. Puertas-Bartolome M, Benito-Garzon L, Fung S, Kohn J, VazquezLasa B, San Roman J. Bioadhesive functional hydrogels: controlled release of catechol species with antioxidant and anti-inflammatory behavior. Mater Sci Eng C. 2019;105:110040. doi:10.1016/j. msec.2019.110040

17. Alavi M, Nokhodchi A. An overview on antimicrobial and wound healing properties of $\mathrm{ZnO}$ nanobiofilms, hydrogels, and bionanocomposites based on cellulose, chitosan, and alginate polymers. Carbohyd Poly. 2020;227:115349. doi:10.1016/j.carbpol.2019.115349.

18. Alavi M, Rai M. Recent progress in nanoformulations of silver nanoparticles with cellulose, chitosan, and alginic acid biopolymers for antibacterial applications. Appl Microbiol Biotechnol. 2019;103 (21-22):8669-8676. doi:10.1007/s00253-019-10126-4.

19. Zhang J, Wang L, Zhou J, et al. Ocular penetration and pharmacokinetics of topical clarithromycin eye drops to rabbits. J Ocular Pharm Therap. 2014;30(1):42-48. doi:10.1089/jop.2013.0042

20. Asthana GS, Sharma PK, Asthana A. In vitro and in vivo evaluation of niosomal formulation for controlled delivery of clarithromycin. Scientifica. 2016;2016:1-10. doi:10.1155/2016/6492953

21. Ameeduzzafar AJ, Bhatnagar A, Kumar N, Ali A, Ali A. Chitosan nanoparticles amplify the ocular hypotensive effect of cateolol in rabbits. Int $J$ Biol Macromol. 2014;65:479-491. doi:10.1016/j. ijbiomac.2014.02.002.

22. Ameeduzzafar QM, Alruwaili NK, Bukhari SNA, et al. BBD-based development of itraconazole loaded nanostructured lipid carrier for topical delivery: in vitro evaluation and antimicrobial assessment. $J$ Pharm Innov. 2020. doi:10.1007/s12247-019-09420-5.

23. Aslam M, Imam SS, Aqil M, Sultana Y, Ali A. Levofloxacin loaded gelrite-cellulose polymer based sustained ocular drug delivery: formulation, optimization and biological study. J Polym Eng. 2016;1-9. doi:10.1515/polyeng-2015-0218.

24. Makoni PA, Chikukwa MTR, Khamanga SMM, Walker RB. Stability indicating HPLC-ECD method for the analysis of clarithromycin in pharmaceutical dosage forms: method scaling versus re-validation. Sci Pharm. 2019;87:31. doi:10.3390/scipharm87040031

25. Papadimitriou S, Bikiaris D, Avgoustakis K, Karavas E, Georgarakis M. Chitosan nanoparticles loaded with dorzolamide and pramipexole. Carbohydr Polym. 2008;73(1):44-54. doi:10.1016/j.carbpol.2007. 11.007 
26. Silva B, Marto J, Braz BS, Delgado E, Almeida AJ, Gonçalves L. New nanoparticles for topical ocular delivery of erythropoietin. Int $J$ Pharm. 2020;576:119020. doi:10.1016/j.ijpharm.2020.119020.

27. Fakhria A, Gilani SJ, Imam SS. Formulation of thymoquinone loaded chitosan nano vesicles: in-vitro evaluation and in-vivo anti-hyperlipidemic assessment. J Drug Deliv Sci Tech. 2019;50:339-346. doi:10.1016/j.jddst.2019.01.033

28. ICCVAM-Recommended Test Method Protocol: Hen's Egg Test Chorioallantoic Membrane (HET-CAM) Test Method. 2010.

29. Ameeduzzafar SS, Bukhari SNA, Ali A, Ali A. Preparation and evaluation of novel chitosan: gelrite ocular system containing besifloxacin for topical treatment of bacterial conjunctivitis: scintigraphy, ocular irritation and retention assessment. Art Cells Nanomed Biotech. 2018;46(5):959-967. doi:10.1080/21691401.2017.1349779.

30. Saini D, Fazil M, Ali MM, Baboota S, Ali J. Formulation development and optimization of raloxifene loaded chitosan nanoparticles for treatment of osteoporosis. Drug Deliv. 2015;22(6):823-836. doi: $10.3109 / 10717544.2014 .900153$

31. Jain A, Thakur K, Sharma G, Kush P, Jain UK. Fabrication, characterization and cytotoxicity studies of ionically cross-linked docetaxel loaded chitosan nanoparticles. Carbohydr Polym. 2016;137:6574. doi:10.1016/j.carbpol.2015.10.012

32. Arafa MG, Girgis GNS, El-Dahan MS. Chitosan-coated PLGA nanoparticles for enhanced ocular anti-inflammatory efficacy of atorvastatin calcium. Int $J$ Nanomedicine. 2020;15:1335-1347. doi:10.2147/ IJN.S237314.

33. Fazil M, Md S, Haque S, et al. Development and evaluation of rivastigmine loaded chitosan nanoparticles for brain targeting. Eur $J$ Pharm Sci. 2012;47(1):6-15. doi:10.1016/j.ejps.2012.04.013.

34. Delan WK, Zakaria M, Elsaadany B, ElMeshad AN, Mamdouh W, Fares AR. Formulation of simvastatin chitosan nanoparticles for controlled delivery in bone regeneration: optimization using boxbehnken design, stability and in vivo study. Int $J$ Pharm. 2020;577:119038. doi:10.1016/j.ijpharm.2020.119038.

35. Tzeyung AS, Md S, Bhattamisra SK, et al. Fabrication, optimization, and evaluation of rotigotine-loaded chitosan nanoparticles for noseto-brain delivery. Pharmaceutics. 2019;11(1):26. doi:10.3390/ pharmaceutics 11010026

36. Katiyar S, Pandit J, Mondal RS, et al. In situ gelling dorzolamide loaded chitosan nanoparticles for the treatment of glaucoma. Carbohydr Polym. 2014;102:117-124. doi:10.1016/j.carbpol.2013. 10.079 .

37. Tsai CH, Wang PY, Lin IC, Huang H, Liu GS, Tseng CL. Ocular drug delivery: role of degradable polymeric nanocarriers for ophthalmic application. Int J Mol Sci. 2018;19(9):2830. doi:10.3390/ ijms 19092830

38. Khan N, Ameeduzzafar KK, Bhatnagar A, Ahmad FJ, Ali A, Ali A. Chitosan coated PLGA nanoparticles amplify the ocular hypotensive effect of forskolin: statistical design, characterization and in vivo studies. Int J Biol Macromol. 2018;30(116):648-663. doi:10.1016/j. ijbiomac.2018.04.122

International Journal of Nanomedicine

\section{Publish your work in this journal}

The International Journal of Nanomedicine is an international, peerreviewed journal focusing on the application of nanotechnology in diagnostics, therapeutics, and drug delivery systems throughout the biomedical field. This journal is indexed on PubMed Central, MedLine, CAS, SciSearch ${ }^{\mathbb{R}}$, Current Contents ${ }^{\mathbb{B}} /$ Clinical Medicine,
39. Nair KL, Thulasidasan AK, Deepa G, Anto RJ, Kumar GS. Purely aqueous PLGA nanoparticulate formulations of Curcumin exhibit enhanced anticancer activity with dependence on the combination of the carrier. Int $J$ Pharm. 2012;425:44-52. doi:10.1016/j. ijpharm.2012.01.003

40. Baklagina YG, Klechkovskaya VV, Kononova SV, et al. Polymorphic modifications of chitosan. Crystallogr Rep. 2018;63(3):303-313. doi:10.1134/S1063774518030033

41. Gondil VS, Dube T, Panda JJ, Yennamalli RM, Harjai K, Chhibber S. Comprehensive evaluation of chitosan nanoparticle based phage lysin delivery system; a novel approach to counter S. pneumoniae infections. Int $J$ Pharm. 2020;573:118850. doi:10.1016/j. ijpharm.2019.118850.

42. Silva MM, Calado R, Marto J, Bettencourt A, Almeida AJ, Gonçalves LMD. Chitosan nanoparticles as a mucoadhesive drug delivery system for ocular administration. Mar Drugs. 2017;15 (12):370. doi:10.3390/md15120370.

43. Zafar A, Khan N, Alruwaili NK, et al. Improvement of ocular efficacy of levofloxacin by bioadhesive chitosan coated PLGA nanoparticles: box-behnken design, in-vitro characterization, antibacterial evaluation and scintigraphy study. Iran J Pharm Res. 2020;19 (1):292-311. doi:10.22037/ijpr.2019.15318.13016.

44. Abdullah TA, Ibrahim NJ, Warsi MH. Chondroitin sulfate-chitosan nanoparticles for ocular delivery of bromfenac sodium: improved permeation, retention, and penetration. Int J Pharm Investig. 2016;6 (2):96-105. doi:10.4103/2230-973X.177823

45. Pardeike J, Weber S, Haber T, et al. Development of an itraconazoleloaded nanostructured lipid carrier (NLC) formulation for pulmonary application. Int J Pharm. 2011;419(1-2):329-338. doi:10.1016/j. ijpharm.2011.07.040

46. Modi J, Joshi G, Sawant K. Chitosan based mucoadhesive nanoparticles of ketoconazole for bioavailability enhancement: formulation, optimization, in vitro and ex vivo evaluation. Drug Dev Ind Pharm. 2013;39(4):540-547. doi:10.3109/03639045.2012.666978

47. Barbi S, Carvalho FC, Kiill CP, Barud S, Santagneli SH, Jose S. Preparation and characterization of chitosan nanoparticles for zidovudine nasal delivery. J Nanosci Nanotechnol. 2015;15(1):865-874. doi:10.1166/jnn.2015.9180

48. Nagarwal RC, Kumar R, Pandit JK. Chitosan coated sodium alginate-chitosan nanoparticles loaded with 5-FU for ocular delivery: in vitro characterization and in vivo study in rabbit eye. Eur $J$ Pharm Sci. 2012;47(4):678-685. doi:10.1016/j.ejps.2012.08.008

49. da Silva SB, Ferreira DF, Pintado M, Sarmento B. Chitosan-based nanoparticles for rosmarinic acid ocular delivery-in vitro tests. Int $J$ Biol Macromol. 2016;84:112-120. doi:10.1016/j.ijbiomac.2015.11.070.
Journal Citation Reports/Science Edition, EMBase, Scopus and the Elsevier Bibliographic databases. The manuscript management system is completely online and includes a very quick and fair peer-review system, which is all easy to use. Visit http://www.dovepress.com/ testimonials.php to read real quotes from published authors. 